\title{
Novas páginas de pesquisa em Psicologia social: o fazer pesquisa na/da internet
}

\author{
New pages in social psychology research: doing research on/from the internet
}

\author{
Flaviane da Costa Oliveira ${ }^{1}$ \\ Jaíza Pollyanna Dias da Cruz Rocha² \\ Ingrid Faria Gianordoli-Nascimento ${ }^{3}$ \\ Luciene Alves Miguez Naiff ${ }^{4}$ \\ Raphael Ferreira de Ávila5
}

\begin{abstract}
RESUMO: As novas tecnologias midiáticas têm revelado formas de comunicação e práticas sociais que desafiam os modos de fazer ciência. O presente estudo explora, de forma inicial, a diversidade de possibilidades de pesquisas em psicologia social compreendendo os recursos virtuais como campo ou objeto de pesquisa. Propomos um mapeamento de produções científicas, a partir do acesso remoto ao portal de periódicos CAPES, tendo sido utilizados na busca, os descritores "social psychology" and internet. Foram encontrados 1042 itens datados entre 1993 e 2016. Os resultados relacionados ao tópico "Social Psychology" totalizaram 289 produções, das quais, analisamos 134 resumos publicados entre 2011 e 2016. As categorias temáticas de maior expressão foram: Comportamento de usuários da internet $(26,12 \%)$ e Identidade e relações intergrupais (11,94\%). Em relação ao método, $17,16 \%$ dos estudos relatam o uso de experimentos, $9,70 \%$ o uso de surveys e 5,97\% questionários. A análise revelou que a maior parte dos estudos $(41,79 \%)$ compreende a internet como objeto de investigação, não sendo apenas um campo ou instrumento facilitador da execução das pesquisas. Apesar de $36,57 \%$ dos trabalhos não situarem a teoria de base, os dados demonstram uma multiplicidade de abordagens teóricas empregadas. Diante da complexidade deste cenário e dos fenômenos nele analisados, desafios teórico-metodológicos se impõem. Consideramos que o detalhamento e descrição do percurso metodológico, o uso da triangulação de métodos e a articulação entre o campo da psicologia social e as teorias da cibercultura, podem potencializar as produções "na" e "da" internet.
\end{abstract}

Palavras-chave: cibercultura; internet; psicologia social; métodos de pesquisa; mapeamento.

ABSTRACT: New media technologies have revealed forms of communication and social practice that challenge ways of doing science. Firstly, the present study explores the diversity of research possibilities in social psychology regarding virtual resources as a field or research object. We propose mapping the scientific production from the remote access to the portal of the CAPES journals. For this purpose we ve used key-words descriptors "social psychology" and internet. We found 1042 items that matched the criteria. The years of publication ranged from 1993 to 2016. Results related to the topic "Social Psychology" presented 289 papers, of which we analyzed 134 published abstracts between 2011 and 2016. The categories with the most important themes were: Internet user behavior (26.12\%) and identity and inter-group relations (11.94\%). In relation

\footnotetext{
${ }^{1}$ Doutoranda em Psicologia pelo Programa de Pós-graduação em Psicologia da Universidade Federal de Minas Gerais. Bolsista pela Coordenação de Aperfeiçoamento de Pessoal de Nível Superior (CAPES) - Belo Horizonte, MG, Brasil. Email: flavianecoliveira@gmail.com.
}

2 Doutoranda em Psicologia pelo Programa de Pós-graduação em Psicologia da Universidade Federal de Minas Gerais. Bolsista pela Fundação de Amparo à Pesquisa do Estado de Minas Gerais (FAPEMIG) - Belo Horizonte, MG, Brasil.

3 Doutora em Psicologia; Docente do Programa de Pós-Graduação em Psicologia e do Departamento de Psicologia da Universidade Federal de Minas Gerais. Financiamento FAPEMIG PPM-00636-16 - Belo Horizonte, MG, Brasil.

4 Doutora em Psicologia pela UERJ e Pós-doutoral em Psicologia Social pela Universidade de Lisboa. Docente da Universidade Federal Rural do Rio de Janeiro (UFRRJ) - Rio de Janeiro, RJ, Brasil.

5 Doutorando da Universidade Federal Fluminense. Mestre em Psicologia pela Universidade Federal Rural do Rio de Janeiro (UFRRJ) - Seropédica, RJ, Brasil. 
to the method, $17.16 \%$ of the studies were experimental, $9.70 \%$ surveys and $5.97 \%$ questionnaires. The majority of studies (41.79\%) considered the internet as a research object, and not just a field or instrument facilitating the execution of research. Although $36.57 \%$ of the studies did not present the base theory, data demonstrates a multiplicity of theoretical approaches employed. Due to the complexity of this scenario and the phenomena itself, methodological challenges are imposed. We considered that detailing and describing the methodological pathway as well as the use of triangulation of methods and articulation between the field of social psychology and theories of cyberculture can stimulate, productions "on" and "from" the internet (that is, using the internet as a research field as well as a research tool).

Keywords: cyberculture; internet; social psychology; research methods; mapping.

\section{Introdução}

A contemporaneidade revela formas de comunicação, relações e práticas sociais que desafiam os modos de fazer ciência. As novas tecnologias midiáticas têm merecido especial interesse em um processo cada vez mais veloz de busca por informações e filiações sociais. 0 caráter imediatista da busca por informações, que nem sempre são verídicas, e a velocidade de circulação das mesmas aponta para a precariedade e fidedignidade do ambiente virtual, levantando críticas sobre sua força na vida real. Mas, pensar somente nestes termos não é suficiente para compreender suas implicações na experiência humana, pois, esse novo modo de vida e interação, lança questões inusitadas acerca da realidade social, que merecem ser exploradas e analisadas.

O homem sempre mediou sua relação com o mundo através de algum nível de simbolização que favorecesse sua existência social. Portanto, não é exagero dizer que tecnologias de comunicação balizam a relação homem-mundo desde os primórdios de sua história, sendo seus avanços verdadeiros marcadores da evolução de nossas sociedades (Lévy, 1996; Lemos, 2015). "Cada forma de vida inventa seu mundo (...) e, com esse mundo, um espaço e um tempo específicos. (...) diversos sistemas de registro e de transmissão (tradição oral, escrita, registro audiovisual, redes digitais) constroem ritmos, velocidades ou qualidades de história diferentes." (Lévy, 1996, p.22, grifos do autor).

Ao dominar a natureza o homem cria um "ecossistema cultural" ou "tecnosfera" (Lemos, 2015, p.31), que é uma "expressão de relações específicas entre a ciência, a filosofia, a sociologia, a economia e a política" (Lemos, 2015, p.39). Ao longo do século XX, a tecnosfera moderna ganhou em complexidade, ampliando seu domínio para a esfera das transações financeiras, mas também emergindo das relações sociais cotidianas.

\footnotetext{
A atual cultura eletrônica não busca mais, como foi o caso da tecnocultura moderna, a dominação técnica da natureza e do social. Trata-se mesmo de uma atitude sociocultural que se expande sobre uma natureza já dominada e transformada em bits e bytes, em espectros virtuais do ciberespaço. Se a tecnocultura moderna foi a forma técnica que emergiu da dominação da natureza (Descartes e Bacon) e da domesticação energética do mundo (Heidegger), a cibercultura, por sua vez, é a forma contemporânea da técnica que joga com os signos desta tecnonatureza construída pela astúcia da tecnocracia. É, ao mesmo tempo, ruptura e continuidade (Lemos, 2015, p.19).
}

Em seu livro precursor intitulado Cibercultura, Lévy (1999) define cibercultura como "conjunto de técnicas (materiais e intelectuais), de práticas, de atitudes, de modos de pensamento e de valores que se desenvolvem juntamente com o crescimento do ciberespaço" (p.17). Neste sentido, a tecnologia empregada torna-se mediadora das relações sociais, ampliando espaços de interação social e territórios (em uma nova acepção de espaço e tempo), dimensão teorizada a partir do conceito de ciberespaço. A origem do termo 
ciberespaço, como vemos em Lévy (1999) e Rüdiger (2013), surge a partir da obra ficcional de William Gibson, intitulada Neuromancer de 1984, ainda que o próprio escritor norteamericano o tenha citado em obra anterior do ano de 1982 (Monteiro, 2007).

Em Gibson (1984/2003), o ciberespaço remete a um mundo em rede com o qual nos conectamos diretamente pela via cerebral, uma alucinação consensual, espaço possibilitado pelo avanço da tecnologia e dos computadores, um palco materializado enquanto plataforma digital urbana onde ocorrem negócios econômicos e culturais. Tal concepção se conecta de algum modo com a realidade atual, ainda que a ficção científica não tenha sido concretizada em sua totalidade.

Tendo realizado uma revisão do conceito de ciberespaço, Monteiro (2007) define-o como:

Um universo virtual proporcionado pelas redes de telecomunicações, mormente a Internet. 0 ciberespaço pode ser concebido, também, como um novo mundo, um novo espaço de significações, um novo meio de interação, comunicação e de vida em sociedade. Esse universo não é irreal ou imaginário, existe de fato, e o faz em um plano essencialmente diferente dos espaços conhecidos (Monteiro, 2007, p.5).

Ainda que, como apontado por Lemos (2015, p.18), atualmente "o termo "ciber" está em todos os lugares", não deve ser representado apenas pelos computadores, mas também por outros equipamentos, como smartphones, tablets, equipamentos de vigilância e comunicação. Sendo a internet elemento destacado na construção de uma nova sociedade que funciona em rede (Castells, 2003). Assim, este trabalho problematiza o tratamento dado a este objeto - a rede mundial de computadores, internet - dentro do campo da Psicologia Social, sendo esta associação solo fértil para a compreensão de aspectos sociais contemporâneos, que não podem negligenciar as mudanças que os avanços e recursos tecnológicos promoveram ao longo das ultimas décadas.

O processo pelo qual a internet e a infraestrutura informática surgiram, foram familiarizadas e incorporadas nas práticas cotidianas de pessoas, famílias e instituições, durante o século XX, como demostrado por variados pesquisadores (Lévy, 1999; Lemos, 2015; Castells, 2003; Rüdiger, 2013), não sendo nosso objetivo atual a revisão completa dessas versões e de suas diferenciações.

Quando o progresso tecnológico e a expansão do capital confluem no sentido da exploração do campo da informática de comunicações, e, por essa via, os aparatos digitais interativos se convertem em bens de consumo de massas, estão configuradas as bases para a expansão de uma cibercultura, da colonização do ciberespaço pelos esquemas e práticas de uma indústria cultural que, desde quase um século, vinha se convertendo em princípio sistêmico de formação do nosso mundo social e histórico (Rüdiger, 2013, p.11).

Ainda que as interações sociais deste mundo virtual ganhem novas características como a velocidade, a ampliação da comunicação com pessoas em diferentes culturas em tempo real e a construção compartilhada de valores e projetos etc. (Monteiro, 2007), o virtual não parece se definir como substituto do real. Deste modo, assim como Lévy (1999) propõe: "a perspectiva da substituição negligencia a análise das práticas sociais efetivas e parece cega à abertura de novos planos de existência, que são acrescentados aos dispositivos anteriores ou os complexificam em vez de substituí-los" (p. 210). Assim, o real e o virtual não se encontram em oposição (Lévy, 1999). As práticas sociais, inauguradas e abandonadas ao longo dos últimos anos, dão prova da fluidez com que os recursos comunicacionais e tecnológicos modificam o cotidiano, sendo também sucessivamente transformados. 
Diante do exposto, em se tratando de pesquisas de psicologia social no universo digital, destacam-se algumas questões levantadas quanto aos aspectos teóricos, identificando os objetos de estudo da área, e aos aspectos metodológicos observados nas pesquisas mapeadas neste estudo.

\section{Do surgimento à expansão: a internet enquanto mediadora de relações sociais}

Para pensar as características dos fenômenos de comunicação contemporâneos, faz-se necessário conhecer o processo histórico no qual o uso, cada vez mais intenso de tecnologias informacionais, impactou a realidade social. Essa história começa quando o homem, em seu constante aprimoramento de instrumentalização para melhor apreender o mundo, cria o universo digital: "a sociedade digital começou a desenvolver-se a partir do surgimento das primeiras máquinas de calcular, no final do século XIX. Os avanços das tecnologias digitais prosseguiram à grande velocidade e, atualmente, há uma utilização massiva dessas novas técnicas" (Monteiro, Carelli, \& Pickler, 2008, p.8).

Ao longo do século XX, mas, principalmente em sua segunda metade, vários esforços foram empreendidos para desenvolver a infraestrutura tecnológica que, segundo Castells (2003) e Lemos (2015), dá origem a uma nova sociedade, na qual o computador torna-se objeto de destaque no cotidiano, saindo dos âmbitos científicos e governamentais e sendo um facilitador de tarefas corriqueiras. Segundo Lévy (1999) o uso de computadores para armazenamento de informações data de 1945, quando Inglaterra e Estados Unidos desenvolveram tecnologias para uso militar. Em tal contexto, o maquinário equivalente ao computador ocupava um amplo espaço físico, eram "grandes máquinas de calcular, frágeis, isoladas em salas refrigeradas" (p.31). Nada que pudesse, aparentemente, lembrar os nanochips e processadores que hoje operam aparelhos, cada vez menores e mais funcionais. O uso civil deste equipamento começaria apenas na década de 1960 (Lévy, 1999; Rüdiger, 2013).

O desenvolvimento de recursos tecnológicos informacionais durante a década de 1960 ganha diferentes abordagens ${ }^{1}$, cabendo situar que seu contexto de surgimento indica interesse e investimento governamental e político americano (Rüdiger, 2013). Além disso, o solo fértil do capitalismo e os princípios morais e ideológicos que regulavam o mercado já estavam em circulação naquela sociedade, viabilizando tal desenvolvimento.

A infraestrutura informática surgiu, foi familiarizada e incorporada nas práticas cotidianas de pessoas, famílias e instituições, durante o século XX (Lévy, 1999; Lemos, 2015; Castells, 2003; Rüdiger, 2013). A descrição deste cenário histórico e social, acerca do uso das tecnologias comunicacionais e informacionais e as dinâmicas sociais envolvidas, potencializam novas questões para o campo da Psicologia Social.

A internet integra vários suportes (multimídia) como: a escrita, a imagem e o som (Lévy, 1999; Silva, 2001; Castells, 2003), surgindo como exercício máximo das formas de prolongamento da existência, impactando as dimensões de espaço e tempo e as dinâmicas de comunicação. Segundo Monteiro, Carelli e Pickler $(2008$, p.8) as sociedades marcadas pela escrita construíram memórias duráveis, registros de longo prazo que devido à "fixidez do signo e do suporte . . . atribuem a esse tipo de memória o caráter de materialidade". O signo no ambiente informatizado é virtualizado, ausente e presentificado em hiperlinks, modificando as dinâmicas psicossociais e as trocas comunicacionais interativas. 
Castells (2003) destaca que a internet nasceu no âmbito do Departamento de Defesa dos Estados Unidos da América, em 1969, - inicialmente chamada de Arpanet, rede de computadores da Advanced Research Projetcts Agency (ARPA) - seu desenvolvimento se deu de forma razoavelmente autônoma, condição pela qual, centros de pesquisa universitários se interessaram pelo projeto. Foi durante a década de 1970, que a comercialização de computadores pessoais ganhou fôlego, iniciando seu uso doméstico. Tal popularização foi preparada por uma série de desenvolvimentos técnicos para a familiarização do equipamento, como por exemplo, a criação do mouse (Lévy, 1999).

Segundo Lévy (1999), nos anos de 1980 a multimídia avançou em áreas como jogos, gravação de músicas, e as primeiras plataformas interativas, sendo o computador transportado gradativamente para as casas, em detrimento do uso exclusivamente industrial.

Após o surgimento da Arpanet, aumentou-se o desenvolvimento técnico e principalmente a padronização de códigos que permitiu a comunicação com outras redes. Um avanço marcado pelo financiamento governamental, mas também fomentado por colaborações de usuários, estudantes e empresas. Assim, ampliou-se o uso militar, criando redes com objetivos específicos, por motivos de segurança. Em 1983, dividiu-se a rede de uso militar MILNET e a ARPA-INTERNET para fins de pesquisa. Em 1990, a Arpanet saiu de operação, pois, iniciava-se a privatização da internet e seu uso no domínio público. A descentralização, os protocolos abertos e as múltiplas camadas que já eram características da Arpanet, foram aspectos que permitiram a integração da internet como conhecemos atualmente (Castells, 2003).

A privatização e a arquitetura aberta da internet (Castells, 2003), juntamente com a infraestrutura de computadores pessoais que já estavam sendo comercializados, bem como, a capacidade de trocas on-line, ganharam maior visibilidade em meados da década de 1990 (Henriques, 2014). A adaptabilidade e mutabilidade dos espaços virtuais (Lévy, 1999) parecem reafirmar-se em constantes revoluções, passando pela "criação da World Wide Web (teia de alcance mundial), por Tim Berners Lee, no começo da década de 90, acompanhada pelo hipertexto 7 operacional" (Monteiro, 2007, p.11), indo da web 1.0 até a criação da web 2.0.

\footnotetext{
No início da internet a participação e a interação dos usuários estava restrita à produção de alguma página pessoal, em código HTML. Com a evolução das mídias de comunicação os usuários passaram, primeiro, a contar com espaços de comentários em matérias de sites de notícias. Em seguida, vieram os blogs, espaços onde qualquer usuário da internet poderia colocar suas experiências online... A etapa seguinte na evolução histórica da internet, com relação à interação com os usuários, foi o surgimento da web 2.0. A ideia por trás do conceito da web 2.0 é justamente a possibilidade de interação do público com a internet, através de wikis, postando vídeos no YouTube ou comentando assuntos em sites de notícias. A criação de espaços de autoria na rede mundial de computadores incentivou o registro e a disponibilização das memórias, sejam elas em forma de texto ou de imagens. As redes sociais substituíram, em larga escala, a experiência das pessoas com os blogs e os comunicadores instantâneos (tais como MSN, ICQ), que eram os grandes atrativos da comunicação mediada pelos computadores na internet 1.0 (Henriques, 2014, p.82).
}

Como destacado por Cabral Filho e Coutinho (2009) e Henriques (2014), o que se modifica nessa passagem entre web 1.0 e web 2.0, não são essencialmente as estruturas ou recursos utilizados, mas a forma de utilização dos conteúdos e do ambiente virtual. Os usuários da rede, nessa segunda fase, estão em busca de velocidade e da possibilidade de não apenas de acessar conteúdos, mas criá-los e alterá-los gratuitamente em interfaces de comunicação e softwares cada vez mais participativos, ou como se convencionou dizer, mais interativos. "A Internet é um espaço de espaços onde o público e o privado, o local e o global, 
- material e o virtual coabitam, o que conduz à geração de novas sociabilidades e reorganização das sociabilidades tradicionais" (Silva, 2001, p.159, grifo do autor).

Compreendemos a internet como uma nova mídia, como veículo de comunicação multimídia (Lévy, 1999), que não representa em si um sinônimo de ciberespaço, mas representa sua principal interface (Monteiro, 2007), tendo a interatividade como característica marcante.

Segundo Mielniczuh (2001), o conceito de interatividade remete a vários significados, nos meios acadêmicos e no senso comum, que circulam os meios de comunicação, sejam os mais tradicionais (com a possibilidade de escolha da programação televisa, ou na escuta de ouvintes no rádio), seja nos cenários digitais (por exemplo, na troca de mensagens). A autora pontua, ainda, uma importante diferenciação entre os meios classificados como reativos e os interativos, mas menciona que esta polarização não dá conta das novas mídias sociais sendo necessário o uso de outras classificações.

Para Lévy (1999, p. 79) “O termo 'interatividade' em geral ressalta a participação ativa do beneficiário de uma transação de informação". O autor postula que as antigas mídias, tais como a televisão, seriam interativas também, pois, suas emissões modificam o expectador, em alguma medida, de modo que para não haver interatividade o receptor da mensagem teria que estar morto. Ainda assim, é de fácil observação à existência de mais interatividade no telefone, se comparado à televisão, pois, este permite a comunicação em "mão-dupla". Em relação aos mundos digitais, estes são mais interativos, pois implicam numa virtualização da presença da pessoa ou de uma situação que pode ser modificada.

Assim, os suportes interativos surgem como possibilidades de comunicação, em uma sociedade que reclama do empobrecimento das relações sociais tradicionais, na família e na comunidade, perpassando uma ideia, que hoje sabemos o quão equivocada é: "o mundo virtual das redes telemáticas surge como uma nova oportunidade, como possibilidade de comunicação aparentemente segura e sem conflitos, enquanto no mundo real os conflitos se multiplicam e a insegurança se instala" (Silva, 2001, p.154). Nesse sentido, as trocas virtuais podem originar relações de solidariedade, afetividade, intimidade, sociabilidade, produção de conhecimento, mas também de exclusão, violência e segregação (Henriques, 2014; Silva, 2000; Lévy, 1999).

Ribeiro (2001) menciona que essas interações possuem novas características, como a troca instantânea de textos, o anonimato e a ausência de referências físicas. Condições que podem variar de acordo com alguns fatores descritos por N. Baym no texto The Emergency of Comunity in Computer-mediated Comunication (como citado em Ribeiro, 2001): os contextos externos, a estrutura temporal do grupo, a infraestrutura do sistema, os propósitos grupais e as características dos participantes. Neste sentido, os espaços virtuais têm se mostrado cada vez mais povoados por grupos e indivíduos que além de produzirem conteúdo, promovem interação e fortalecem vínculos de pertencimento que rompem com as dinâmicas de espaço e tempo tradicionais, fomentando a construção/fortalecimento de identidades e representações partilhadas.

O crescimento da internet atinge todas as partes do globo, mas seu uso permanece limitado e dependente de recursos financeiros, por isso, tratar desse tema implica diferenciações regionais e sociais (Castells, 2003). Na América Latina, Fragoso e Maldonado (2009) destacam o crescimento intenso do número de usuários na primeira década do século XXI. Ainda assim, nota-se que os países com maior concentração de renda são aqueles que 
apresentam o maior número de usuários - dentre eles, no caso da América Latina, encontrase o Brasil.

Além dos usuários domésticos da internet, percebe-se também a melhoria da infraestrutura dos serviços, principalmente ampliando o acesso chamado banda larga, e também a ampliação de tele-centros que garantem o acesso gratuito ou facilitado para pessoas economicamente desfavorecidas. Desse modo, cabe salientar que: "deve ser questionada a ideia de que a grande maioria da população da América Latina não tem ideia do que seja a internet, também não é verdade que 'as elites urbanas da América Latina, agora têm acesso fácil a internet'" (Fragoso \& Maldonado, 2009, p.29). São diversos os extratos da população que têm buscado o acesso a internet devendo-se analisar, com cuidado, as variáveis que influenciam cada contexto, bem como, compreender essa realidade como fenômeno presente e que tem impactos abrangentes nas práticas sociais.

\section{As mídias e as redes sociais no cotidiano brasileiro}

Neste item ressaltamos algumas considerações acerca das mídias e sua relação com o cotidiano. No Brasil, a partir da base amostral de 33,2 milhões de domicílios, a proporção de residências com computador passou de $25 \%$ para 50\% entre 2008 e 2015, atingindo metade da população. O acesso à internet mais que dobrou, indo de $18 \%$ para $51 \%$ conforme declarado pelos brasileiros, ampliando-se, ainda, o acesso à internet por meio da telefonia móvel que passou a ser analisada desde 2014. Ainda que o número de usuários varie conforme escolaridade e renda, há crescimento em todas as faixas analisadas (NIC.br, 2016). Tal cenário leva a crer que a conectividade começa a torna-se parte indissociável da vida contemporânea.

Se incluirmos as mídias de grande circulação, percebemos um país marcado pelo oligopólio midiático, no qual se estima que aproximadamente $70 \%$ dos veículos de comunicação estejam sobre a tutela de 6 grandes empresas, as relações da mídia tradicional têm influência direta sobre vida política, e demarcam questões que podem ser colocadas sobre a cultura das manifestações públicas construídas no país nos últimos 20 anos (Ávila \& Monteiro, 2014).

$\mathrm{Na}$ indústria televisiva, três dessas empresas têm maior peso: a família Marinho (proprietária da Rede Globo, que deteria 38,7\% do mercado), o bispo da Igreja Universal do Reino de Deus, Edir Macedo (maior acionista da Rede Record, 16,2\% do mercado) e Silvio Santos (proprietário do SBT, e 13,4\% do mercado). A família Marinho também é proprietária de emissoras de rádio, jornais e revistas - campo em que concorre com Roberto Civita, que domina o Grupo Abril (ambos detêm cerca de 60\% do mercado editorial). Famílias também controlam os principais jornais brasileiros - como os Farias, donos da Folha de S.Paulo, e os Mesquita, de $\mathrm{O}$ Estado de S. Paulo (ambos entre os cinco maiores jornais do país). No Rio Grande do Sul, a família Sirotsky é dona do grupo RBS, que controla o jornal Zero Hora, além de TVs, rádios e outros diários regionais. Famílias ligadas a políticos tradicionais estão no comando de grupos de mídia em diferentes regiões, como os Magalhães, na Bahia, os Sarney, no Maranhão, e os Collor de Mello, em Alagoas².

Ainda que a mídia de massa tenha expressão no Brasil, em número de espectadores, ouvintes e leitores, as redes sociais digitais tem encontrado cada vez mais capilaridade, revelando uma nova posição dos indivíduos diante da comunicação. Agora atuam principalmente agrupando, não mais em massa homogênea, aqueles que se dispõem a tomar 
participação em suas comunidades, blogs, sites, e todo tipo de manifestação possível na internet. Permitem a produção de um discurso que emerge, trazendo à superfície singularidades do coletivo, antes submersas sob a coletividade. Portanto, surgem como elemento principal de institucionalização na dinâmica dos atuais fenômenos (Ávila \& Monteiro, 2014).

As manifestações de junho de 2013, uma das primeiras manifestações geradas no ambiente virtual no Brasil, se tornou uma das principais movimentações de massa criadas e alimentadas em um ambiente virtual de fato, em que as grandes mídias não tinham grande ascensão (Ávila \& Monteiro, 2014).

Estas novas mídias são importantes na crítica do funcionamento operacional da sociedade e seus dispositivos. Dos aglutinadores e participantes das manifestações de junho de 2013 no Brasil, a maior parte era formada pela juventude que, em comum, compartilhava o contato com as redes sociais, e por lá, foi inicialmente convocada, evidenciando um sistema independente do controle da mídia tradicional.

Um dos campos mais férteis de pesquisa atualmente, em que representações sociais, crenças, sentimentos, valores e opiniões são amplamente repassados, construídos e discutidos é a rede social Facebook [https://www.facebook.com/], encontrada em sua versão em português no endereço eletrônico [https://pt-br.facebook.com/].

Lançado em 4 de fevereiro de 2004, a rede social é de propriedade privada da empresa Facebook Inc., que atualmente conta com mais de 1 bilhão de usuários ativos registrados, sendo que 76 milhões destes estariam no Brasil, segundo maior participante em números absolutos, atrás apenas dos Estados Unidos da América (Lima, 2014). Considerando os dados relativos ao Censo de 2010, o Brasil contabilizaria 201 milhões de habitantes, e assim 37,8\% dos brasileiros estariam conectados à rede colaborativa, ou seja, uma a cada três pessoas.

Sua história mostra que o Facebook não nasceu com o intuito de ser uma ferramenta aberta e global de diálogo, mas sim, restrita a um grupo específico - no circuito universitário de seu fundador Mark Zuckerberg, inicialmente na Universidade de Harvard. Tal lógica, iniciada por seus criadores, parece ponto importante a se considerar, a fim de compreender a maneira como a rede social segue sendo dirigida. Muitas das características contraditórias e pouco democráticas, no sentido de livre expressão, do sigilo e da abertura de informações privadas à forças de segurança pública durante investigações, por exemplo, aparentam ser consequências de políticas, desde a fundação do serviço, e que não acompanharam as mudanças tecnológicas de sua expansão. Ressalta-se que o Facebook se consolida no meio virtual, ou ainda como ferramenta de um padrão cultural, como relevante e aparentemente pouco usado objeto para pesquisas acadêmicas, o que requer ainda análises mais aprofundadas.

Apesar das críticas que se possam traçar a partir de sua origem, a rede social acabou tornando-se uma ferramenta mundial de organização de lutas a favor de mudanças políticas e sociais. Assim, o espaço virtual aparece como um campo de criação, permanência e resistência de movimentos sociais, fortalecendo os ideias e sentimentos grupais, em prol dos objetivos que se propõem.

Os avanços tecnológicos, o advento da internet e os recursos colaborativos da web, modificam significativamente as formas dos grupos sociais se expressarem e oferecem novos contornos às manifestações coletivas que passam a ir além das antigas fronteiras espaço-temporais e alcançam potenciais expressivos de organização social (Araújo, 2011, p.2). 
Em 2007, a capacidade de mobilização de grupos sociais no ciberespaço, provocou a proibição do uso do Facebook na Síria. Em 2009, foi a vez da China impor bloqueio aos serviços da empresa, em uma tentativa de suprimir informações sobre protestos que lá estavam emergindo. A rede social Facebook aparece para os manifestantes, como mídia alternativa, e os exemplos são os mais diversos, principalmente em países nos quais a censura à informação é parte do cotidiano e o governo interfere nos meios de comunicação em massa (Lima, 2014). Em 2008, organizações de direitos humanos criticaram o Irã por impedir, energicamente, a liberdade de expressão e implodir plataformas de interação social. No entanto, a emergência da internet como um meio global tem desafiado os esforços estatais autoritários para monitorar a circulação de informação. A web se tornou uma ferramenta para expressar visões político-sociais que não conseguem escapar dos filtros da grande mídia.

Janeiro de 2011 teria sido o mês em que o Facebook teve enorme participação ao gerar as primeiras fagulhas para a revolta egípcia (Lima, 2014). No Brasil, os protestos de junho de 2013 contra o aumento das tarifas do transporte público, organizados principalmente por meio da plataforma da empresa de Zuckerberg, levaram milhões de pessoas às ruas por todo o país, além de servir como fonte essencial de disseminação de textos, fotos e vídeos do uso desproporcional da força policial, o que deu cada vez mais abrangência aos movimentos e os ajudou a ganhar o apoio da opinião pública. O resultado das ações foi a revogação dos aumentos tarifários em muitas capitais e em boa parte de cidades menores.

Ainda que o Facebook e outras redes sociais apresentem-se de forma promissora como pontes para cooperação, articulação política e participação social em uma jovem democracia como a brasileira, o pesquisador desse fenômeno deve manter-se atento para não se deixar influenciar por uma leitura tecnófila, ou seja, que compreende a cibercultura e a tecnologia unicamente como salvação e progresso para a humanidade (Hüdiger, 2013). Nesse sentido, "Subjacente aos fenômenos da cibercultura, encontra-se, portanto, o contexto de um capitalismo violento, que se tornou onipresente e planetário, quer no espaço real, quer no ciberespaço" (Hüdiger, 2013, p.280).

Entendendo as complexas dinâmicas das interações e relações estabelecidas no ciberespaço, a psicologia social pode contribuir para a construção de uma leitura crítica dos fenômenos da cibercultura, ao identificar que nos cenários de interação nela existentes os sujeitos podem atuar de forma a promover valores democráticos ou autoritários, bordejados por uma lógica mercadológica promovida pelas instituições que ali subjazem e que não pode ser esquecida. Ainda que a internet reproduza, muitas vezes, o conteúdo hegemônico da cultura de massa ou mesmo um cenário mercantilizado, rico em publicidade, acreditamos como Hüdiger (2013), que o estudo da cibercultura tomada de forma crítica e situada historicamente pode nos ajudar na compreensão de nosso tempo.

\section{O campo de pesquisa sobre a internet}

As mídias sociais têm evoluído constantemente, contribuindo de forma importante para o desenvolvimento da sociedade. Dentre as mais difundidas entre os usuários da internet, estão as redes sociais. Atualmente, encontramos a aplicação das redes sociais em diversas áreas das ciências, seja na área de Tecnologia da Informação e das Comunicações, no Marketing, Sociologia, entre outras. Entretanto, ainda tramita no Brasil uma regulação que vigora sobre pesquisas acadêmicas ou comerciais na internet: O Marco Civil para Internet. Sancionado em Abril de 2014 pelo Congresso Nacional, após ampla consulta popular e 
participação de movimentos sociais, o projeto aguarda agora que o governo elabore um decreto com o qual regulará, entre outros aspectos, as exceções ao princípio da neutralidade da rede. Espera-se também que por meio de um decreto a regulação de aspectos como a manutenção de registros de conexão por parte das operadoras e a privacidade dos usuários na internet. Tal projeto pretende ainda estabelecer princípios como a segurança, a transparência e a "finalidade específica" dos dados, o que significa que as empresas poderão usar apenas as informações para o objetivo único para o qual foram autorizadas pelos usuários. O texto também deve tratar questões como vazamento de dados, as boas práticas, o uso partilhado das informações e as possíveis sanções administrativas. Por enquanto, as pesquisas na internet seguem sem regulamentação no país, o que nos implica justapor os princípios éticos profissionais e científicos como em qualquer outro trabalho de pesquisa acadêmica.

Ainda assim, no campo das ciências humanas e sociais já existe um panorama quanto à entrada da internet e das redes sociais como base para a pesquisa acadêmica. A possibilidade de investigar os discursos presentes na rede mundial de computadores carrega um potencial de contribuição para o campo de investigações em Psicologia Social, trazendo elementos sobre as relações entre tecnologia, meios de comunicação e interação social, argumento defendido pelo próprio Moscovici em entrevista (Casalagno, 2006). Em relação ao campo de estudos da abordagem psicossocial da memória, por exemplo, afirma-se que os elementos históricos permanecem sendo negociados pelos grupos sociais, no âmbito das conversações e práticas sociais, seja através da comunicação direta entre os interlocutores ou a partir da mediação de recursos tecnológicos; mas tais aspectos são pouco priorizados nas discussões entre psicólogos(as) sociais.

Fragoso, Recuero e Amaral (2011) se dedicaram a compreender como as ciências sociais têm tratado a pesquisa sobre a internet, problematizando-a enquanto disciplina, campo ou objeto de pesquisa. De modo amplo, as autoras observam que a internet, enquanto objeto, é difícil de ser analisada isoladamente por um único campo de saber, sendo que gradualmente, sua investigação vem ganhando centralidade em várias disciplinas.

\footnotetext{
...internet pode ser tanto objeto de pesquisa (aquilo que se estuda), quanto local de pesquisa (ambiente onde a pesquisa é realizada) e, ainda, instrumento de pesquisa (por exemplo, ferramenta para coleta de dados sobre um dado tema ou assunto) (Fragoso, Recuero, \& Amaral, 2011, p.17).
}

Deste modo, a partir da revisão de vários trabalhos, as autoras revelam que a internet pode ser encarada em perspectivas diferentes, como campo ou objeto de pesquisa. Em uma perspectiva qualitativa de base etnográfica, por exemplo, pode ser vista enquanto cultura, artefato cultural ou mídia, com destaque para temas como as identidades on-line, as relações entre grupos, o corpo, recursos de comunicação, audiência e produção de conteúdos etc. Muitos dessas temáticas marcam o início das investigações em ciências sociais diante do surgimento da internet, mas perspectivas quantitativas ou mesmo novas metodologias podem e vem sendo empregadas.

Em termos históricos, Fragoso, Recuero e Amaral (2011) retomam algumas análises sobre os estudos em internet, indo do surgimento (hipe ou moda) da internet à sua investigação em dinâmicas cada vez mais complexas. Conforme Barry Wellman em The three ages of internet studies: tem, five and zero years ago (como citado em Fragoso, Recuero, \& Amaral, 2011) as produções sobre a internet podem ser divididas a partir de suas características, em três etapas: 1a etapa (até 1998), quando a internet é tratada enquanto 
fenômeno comunicativo; 2a etapa (após 1998), momento em que são empregadas pesquisas de opinião, surveys, entrevistas e técnicas de documentação na observação de usuários e práticas sociais; 3a etapa (início dos anos 2000) quando iniciam-se análises teóricometodológicas dos dados.

Já em Internet ethnography - notes for a presentation de John Postill - como também apresentado por Fragoso, Recuero e Amaral (2011) - os estudos sobre a internet podem ser divididos historicamente em três conjuntos: 1) Década de 1990: com a presença de estudos sobre surgimento da internet e a polarização real-virtual; 2) Segunda metade da década de 1990: período no qual investiga-se a internet no cotidiano e como as pessoas utilizam o próprio tempo frente a internet (discussão muito presente nas pesquisas anglo-saxônicas); 3 ) Anos 2000: momento no qual encontramos objetos com dinâmicas e lógicas próprias no universo da internet.

De modo amplo, observamos que como fenômeno novo, a internet é compreendida, em um primeiro momento em seu aspecto comunicacional e nas mudanças que tal instância promove na construção social da realidade, assim, num segundo momento, tal utilização é problematizada em relação ao tempo gasto com esse espaço de interação, sendo também um ambiente usado como campo de pesquisa; já num terceiro momento os dados passam a ser mobilizados enquanto detentores de uma lógica e configurações próprias. Ainda assim, Fragoso, Recuero e Amaral (2011) destacam que as revisões propostas pelos autores precisam ser relativizadas, pois, se referem em grande parte ao contexto anglo-saxônico, sendo que as pesquisas no Brasil ganham corpo durante os anos 2000.

No âmbito da psicologia social, observa-se a ausência de abordagem semelhante para este problema de pesquisa - a saber, conhecer as características dos estudos sobre a internet. A partir do esforço observado em pesquisas das ciências sociais e da comunicação (Fragoso, Recuero, \& Amaral, 2011; Amaral \& Montardo, 2010, 2011) propomos um mapeamento de produções científicas no campo da Psicologia, com ênfase naquelas referidas como relativas à Psicologia Social. A partir de um levantamento no portal de periódicos CAPES, descreveremos aspectos teórico-metodológicos do material, compreendendo se a internet é descrita enquanto campo ou objeto de pesquisa e fomentando novas questões.

\section{Método}

A partir do acesso remoto ao portal de periódicos CAPES, como usuário de instituição de nível superior de ensino, a saber, a Universidade Federal de Minas Gerais, foi realizada busca por assunto, a partir dos descritores "social psychology" and internet. A coleta de dados foi realizada durante o mês de outubro de 2016. A partir dos resultados da busca observamos a frequência do perfil de produção em termos de tipo/formato (Tabela 1), idioma (Tabela 2) e a área de conhecimento. Empregamos uma leitura exploratória dos resumos relativos a área Psicologia Social, a fim de categorizar os temas investigados, os aportes teóricos e os principais recursos metodológicos utilizados.

\section{Resultados e discussão}

Tendo em vista o crescimento do interesse dos pesquisadores brasileiros pela internet, o mapeamento realizado neste estudo evidenciou os seguintes resultados: 1042 itens obtidos 
através da busca com os descritores "social psychology" and internet datados entre 1993 e 2016. Deste total, 975 produções originavam-se de periódicos revisados por pares, garantindo maior qualidade e confiabilidade à divulgação científica. As tabelas abaixo apresentam o número de produções divididas por formato (Tabela 1) e idioma (Tabela 2).

Tabela 1 - Formato das produções, Portal de periódicos CAPES (1993-2016).

\begin{tabular}{lll}
\hline Formato & Frequência & \% \\
\hline Resenhas & 15 & 1,44 \\
Artigos de jornal & 7 & 0,67 \\
Artigos & 1000 & 95,97 \\
Recursos textuais & 11 & 1,05 \\
Dissertações & 3 & 0,29 \\
Outras opções & 6 & 0,58 \\
\hline Total & $\mathbf{1 0 4 2}$ & $\mathbf{1 0 0}$ \\
\hline
\end{tabular}

Tabela 2 - Idioma das produções, Portal de periódicos CAPES (1993-2016).

\begin{tabular}{lll}
\hline Idioma & Frequência & \% \\
\hline Alemão & 19 & 1,82 \\
Português & 6 & 0,58 \\
Inglês & 1003 & 96,26 \\
Espanhol & 9 & 0,86 \\
Japonês & 5 & 0,48 \\
\hline Total & $\mathbf{1 0 4 2}$ & $\mathbf{1 0 0}$ \\
\hline
\end{tabular}

A ampla maioria $(95,97 \%)$ das investigações encontra-se divulgada no formato de artigo científico. Grande parte dos estudos foram publicados em inglês, idioma predominante na divulgação científica. $O$ número de produções divulgadas em língua portuguesa, não chega a atingir $1 \%$ da amostra.

Os resultados relacionados ao tópico "Social Psychology" totalizaram 289 produções, dos quais 134 publicados entre 2011 e 2016. Os resumos destes trabalhos foram analisados e os principais aspectos encontrados serão destacados a seguir.

Em relação aos temas investigados, foram elaboradas 13 categorias temáticas (Tabela 3), sendo a mais representativa a que engloba os estudos sobre "Comportamento de usuários da internet", achado que corrobora a análise histórica de Postill (como citado por Fragoso, Recuero, \& Amaral, 2011), ao descrever as características dos estudos pós anos 2000. Essa categoria inclui estudos sobre relacionamentos on-line, atração e interação entre usuários, consumo na internet, privacidade nas redes sociais, uso de avatar, relação entre on-line offline. Tendo em vista a importância da interação social enquanto objeto de estudo da psicologia social, estuda-la no ambiente virtual é uma forma de reconhecer que não se sustenta a dicotomia entre espaço "real" e espaço "virtual", pois, o virtual não se opõe ao real, sendo apenas um complexificador do mesmo (Lévy, 1999).

O ciberespaço configura-se como um cenário de sociabilidades, trocas, negociações econômicas, simbólicas e afetivas (Ribeiro, 2001; Silva, 2001; Henriques, 2014). Tais características são ainda encontradas nos estudos relativos às categorias "Emoções" (que inclui estudos sobre motivação, ansiedade social), "Facebook (uso e acesso da rede social), "Comunicação" (a tecnologia como mediadora da linguagem, criação de códigos linguísticos 
na internet), "Identidade e relações intergrupais" (inclui interação entre indivíduos e grupos, estudos comparativos sobre grupos on-line e off-line; processos identitários, de inclusão e exclusão social, participação em jogos virtuais).

As categorias "Cyberbulling", "Saúde" (estudos sobre práticas de cuidado, saúde mental, corpo) e "Prejuízos do uso da internet (estudos sobre adição/uso abusivo de plataformas virtuais; dispêndio de tempo, patologias impulsionadas pelo excessivo da internet), reafirmam características identificadas nos estudos de Postill e Wellman (como citado por Fragoso, Recuero, \& Amaral, 2011), relativos ao fenômeno da internet no final da década de 1990, quando estudos sobre o tempo gasto com o meio virtual foram tomados como prejudiciais à interação social, ainda pautada na dicotomia real-virtual. A cibercultura e o acesso a seus recursos, são tomados atualmente como característica de nosso tempo e o número de interfaces interativas aumentaram não somente em quantidade, como promoveram novas práticas sociais (Lemos, 2015). Ainda assim, a preocupação com o tempo gasto nesse ambiente têm se mantido nas agendas de pesquisa, sustentando, em certa medida, a dicotomia real-virtual e as possíveis consequências negativas da virtualidade para as esferas produtivas (trabalho e educação).

Contudo, ainda que de forma minoritária, os estudos analisados permitem a observação de aspectos positivos do uso da internet, refletidos nas categorias "Benefícios do uso da internet" (inclui estudos sobre ajuda online, cooperação, papel de comunidades virtuais), "Ação Coletiva" e "Ciberativismo", as duas últimas refletindo aspectos da participação política e fortalecimento dos movimentos sociais e identidades coletivas, a partir do ambiente virtual.

Tabela 3 - Categorias temáticas dos estudos em Psicologia Social, Portal de periódicos CAPES (2011-2016).

\begin{tabular}{lll}
\hline Categoria & Frequência & \% \\
\hline Atitude & 6 & 4,48 \\
Benefícios do uso da internet & 5 & 3,73 \\
Cyberativismo & 4 & 2,99 \\
Comportamento de usuários da Internet & 35 & 26,12 \\
Comunicação & 11 & 8,21 \\
Cyberbulling & 6 & 4,48 \\
Emoções & 10 & 7,46 \\
Facebook & 4 & 2,99 \\
Identidade e relações intergrupais & 16 & 11,94 \\
Personalidade & 5 & 3,73 \\
Preconceito & 5 & 3,73 \\
Prejuízos do uso da internet & 10 & 7,46 \\
Outros & 17 & 12,69 \\
\hline Total & 134 & $\mathbf{1 0 0}$ \\
\hline
\end{tabular}

Em relação aos assuntos pesquisados no Brasil e Estados Unidos entre 2000 e 2010, em levantamento do material produzido no campo da comunicação, a partir da análise de anais de eventos científicos dos dois países, Amaral e Montardo (2010, p.66) revelam como principais temas de estudo: Linguagem; Crítica da técnica do imaginário tecnológico; Subjetividade; Apropriação Tecnológica; Economia Política da Comunicação mediada por computador; Ciberativismo; Epistemologia; Imaginário tecnológico; Inclusão digital; Práticas de Consumo Mercadológico; Socialização online. Amaral e Montardo (2010) destacam que muitos desses temas são aludidos em conjunto nos trabalhos e trata-se de um campo em 
movimento, cuja descrição completa é inviável. Tal levantamento foi ampliado pelos autores com a análise de outro evento da área, tendo sido consolidadas as temáticas do Jornalismo Digital e do Entretenimento Digital, anteriormente incluídas nas categorias: Apropriação Tecnológica, Sociabilidade (socialização online) e Linguagem (Amaral \& Montardo, 2011).

Observamos que apesar de se referirem a áreas de saberes diferentes, o levantamento aqui proposto e aqueles desenvolvidos por Amaral e Montardo (2010, 2011), corroboram as esferas da interação social, comunicação, participação política e das práticas de consumo, dentre outros, demonstrando o alinhamento dos interesses de estudos no ambiente virtual.

Uma carência explicitada na análise dos resumos refere-se a ausência da indicação das abordagens teóricas em número expressivo do conjunto analisado. Apesar de 36,57\% dos trabalhos não situarem a teoria de base, os dados demonstram uma multiplicidade de abordagens teóricas empregadas (Tabela 4). Foram construídas 35 categorias englobando as diferentes teorias observadas, porém, convém situar a pulverização dos elementos teóricos, já que nenhuma das categorias supera $10 \%$ da amostra total. Para a categorização foram consideradas as menções diretas a uma teoria de base ou a existência de conceitos ou elementos teóricos no corpo do resumo. A categoria "Não identificado" reúne os itens que não apresentam ou nos quais não foi possível classificar o campo teórico a que se filiam.

Tabela 4 - Teorias de base dos estudos em Psicologia Social, Portal de periódicos CAPES (2011-2016).

\begin{tabular}{|c|c|c|}
\hline Teoria & Frequência & $\%$ \\
\hline Ação coletiva & 4 & 2,99 \\
\hline Ação comunicativa & 5 & 3,73 \\
\hline Afiliação compensatória & 1 & 0,75 \\
\hline Aprendizagem & 1 & 0,75 \\
\hline Atitude & 7 & 5,22 \\
\hline Atribuição causal & 3 & 2,24 \\
\hline Comportamento social & 5 & 3,73 \\
\hline Identidade & 8 & 5,97 \\
\hline Influência social & 6 & 4,48 \\
\hline Interação Social & 2 & 1,49 \\
\hline Personalidade & 5 & 3,73 \\
\hline Pós-coloniais e feministas, estudos de mídia e culturais & 1 & 0,75 \\
\hline Preconceito & 4 & 2,99 \\
\hline Psicologia cognitiva & 1 & 0,75 \\
\hline Psicologia cultural & 1 & 0,75 \\
\hline Psicologia da imigração e da saúde mental familiar & 1 & 0,75 \\
\hline Psicologia do aconselhamento & 1 & 0,75 \\
\hline Psicologia do desenvolvimento & 1 & 0,75 \\
\hline Psicologia social & 12 & 8,96 \\
\hline Psicologia transcultural & 2 & 1,49 \\
\hline Teoria cultural e de cognição & 1 & 0,75 \\
\hline Teoria da acomodação de comunicação & 1 & 0,75 \\
\hline Teoria da autodeterminação & 1 & 0,75 \\
\hline
\end{tabular}




\begin{tabular}{llc} 
Teoria da motivação intrínseca & 1 & 0,75 \\
Teoria da troca social e teoria da inovação e dinâmica da organização & 1 & 0,75 \\
Teoria das alocações & 1 & 0,75 \\
Teoria de preferências relativas, teoria prospectiva e aversão a perdas & 1 & 0,75 \\
Teoria do campo & 1 & 0,75 \\
Teoria do Comportamento Planejado (TPB) & 1 & 0,75 \\
Teoria do fluxo & 1 & 0,75 \\
Teoria dos valores humanos & 1 & 0,75 \\
Teoria integrativa & 1 & 0,75 \\
Teoria Social Cognitiva (SCT) e da Teoria da Confirmação de Expectativa (ECT) & 1 & 0,75 \\
Teorias psicodinâmicas e psicologia social & 1 & 0,75 \\
Não identificado & 49 & 36,57 \\
\hline Total & 134 & $\mathbf{1 0 0 , 0 0}$ \\
\hline
\end{tabular}

Já em termos metodológicos, Fragoso, Recuero e Amaral (2011) apontam que apesar dos desafios desse novo campo, "não é preciso abandonar a pesquisa empírica, mas reinventar nossos processos e técnicas" (p.11), tendo sido identificados o uso de métodos consolidados no âmbito das ciências sociais, tais como, análise de conteúdo, de discurso, etnografia, análise documental, estatísticas e estudos de caso, dentre outros para o tratamento de material advindo de Blogs, páginas pessoais, websites, portais, redes sociais, fóruns, etc.

No mapeamento por nós proposto observamos a predominância dos estudos empíricos, em que se destacam as investigações de cunho experimental $(17,16 \%)$, a utilização de surveys $(9,70 \%)$, o uso de jogos $(7,46 \%)$ e questionários $(5,97 \%)$. A observação destas estratégias metodológicas se deu pela observação direta dos elementos citados literalmente nos resumos.

Diante da complexidade deste cenário e dos fenômenos nele analisados, desafios teórico-metodológicos se impõem. Consideramos que o detalhamento e descrição do percurso metodológico, o uso da triangulação de métodos e a articulação entre o campo da psicologia social e as teorias da cibercultura, podem potencializar as produções "na" e "da" internet.

Neste sentido, durante a análise dos dados construímos uma variável que classificou os itens em quatro perfis: pesquisas "na" internet (investigações sobre temas diversos com o uso da internet como local de coleta); pesquisa "da" internet (investigações de objetos da cibercultura); pesquisas mistas (interesse pela internet como campo e objeto de investigação, muitas vezes com comparações entre os meios on-line e off-line ou buscando compreender como determinado fenômeno se comporta na internet) e pesquisas em que não foi possível classificar o trabalho a partir dos elementos do resumo (perfil não identificado).

A análise revelou que a maior parte dos estudos (41,79\%) compreende a internet como objeto de investigação, não sendo apenas um campo ou instrumento facilitador da execução das pesquisas. 
Tabela 5 - Pesquisas "na" e "da" internet em Psicologia Social, Portal de periódicos CAPES (2011-2016).

\begin{tabular}{lll}
\hline Categoria & Frequência & \% \\
\hline Pesquisas "na" internet & 28 & 20,90 \\
Pesquisa "da" internet & 56 & 41,79 \\
Pesquisas mistas & 26 & 19,40 \\
Não identificado & 24 & 17,91 \\
\hline Total & $\mathbf{1 3 4}$ & $\mathbf{1 0 0}$ \\
\hline
\end{tabular}

Assim, observamos a existência de duas tendências no âmbito de investigações em Psicologia social relativas à Internet (Quadro 1):

\begin{tabular}{|c|c|}
\hline Pesquisa "na" internet & Pesquisa "da" internet \\
\hline $\begin{array}{l}\text { - Ciberespaço: pano de fundo (local de coleta de } \\
\text { dados). } \\
\text { - Uso do cenário como facilitador metodológico e de } \\
\text { recursos. } \\
\text { - Temas diversos, sem relação direta com as } \\
\text { discussões sobre cibercultura. }\end{array}$ & $\begin{array}{l}\text { - Processos psicossociais no ciberespaço como } \\
\text { objeto de estudo. } \\
\text { - Espaço para novas perguntas e reconhecimento de } \\
\text { novas dinâmicas advindas desse contexto. } \\
\text { - Resultados são marcados pelo contexto de } \\
\text { construção. } \\
\text { - Reconhecer novos documentos como fontes } \\
\text { (imagens, vídeos etc.) }\end{array}$ \\
\hline
\end{tabular}

Quadro 1 - Análise da produção em Psicologia Social sobre a Internet, Portal de Periódicos CAPES (2011-2016).

A divisão proposta ainda se ensaia como princípio organizar, mas cabe salientar que nem sempre a classificação dos estudos é tarefa simples. Alguns estudos apresentam um caráter intermediário ou misto (como salientado na categoria Pesquisas Mistas), na medida em que, analisam processos psicossociais nascidos no cenário tradicional, identificando-os no espaço virtual, mas sem aprofundar a análise deste aspecto e/ou elucidar em seus resultados como o ciberespaço teve impacto nas dinâmicas analisadas. Essa perspectiva situa-se num continuum entre as pesquisas que tomam a internet como instrumento, local ou objeto de pesquisa (Fragoso, Recuero, \& Amaral, 2011).

Não se pretende uma hierarquização entre os estudos "da" e "na" internet, ainda que o número de produções que problematizem as implicações do virtual nos processos psicossociais indique um campo aberto de possibilidades. A sociedade atual e a "primazia factual ao código visual" (De Rosa, 2005, p.131) revela novas dinâmicas de comunicação e interação pouco exploradas. As dinâmicas identitárias e processos de construção de memórias sociais no ambiente virtual parecem representar campos úteis de investigação. As implicações de alguns marcadores socais na interação virtual ainda parecem pouco exploradas, como por exemplo, em relação a geração.

\section{Considerações finais: desafios da pesquisa em psicologia social na contemporaneidade}

A pesquisa em psicologia social que pressupõe, dentre diversos aspectos, compreender de que forma as relações interpessoais afetam e são afetadas em sua dinâmica, não pode mais 
prescindir desse universo de trocas sociais que é a internet. Seja para buscar informações, conhecer pessoas e lugares, criar grupos identitários, produzir representações sociais e difundir ideologias, as pessoas e os grupos pensam, acreditam, sentem e agem atualmente também através do uso desse recurso.

Alguns grupos sociais só se reúnem virtualmente, vinculando-se psicologicamente por laços ideológicos, políticos, práticos ou identitários. Grupos sociais que se "tribalizam" em identidades sociais que não estão mais territorializadas ou assentadas nas dimensões concretas de tempo e espaço. Assim, se um dos principais objetos da psicologia social são as interações sociais, as pesquisas deverão estar onde quer que elas aconteçam.

Desafios metodológicos se impõem, estratégias de pesquisas precisam ser revisitadas e realinhadas a esses novos formatos. Nesse sentido, a descrição criteriosa do desenho metodológico empregado nas investigações, necessita ser considerada, pois, o fazer pesquisa sobre a internet no âmbito da psicologia social, implica procedimentos de coleta e análise de dados a serem reinterpretados a partir das características do ciberespaço.

Diante da complexidade deste cenário e dos fenômenos nele analisados, a triangulação metodológica pode ser uma estratégia de apoio à pesquisa "na" internet e "da" internet. A triangulação de dados se refere mais a busca por múltiplos lugares e níveis para o estudo do fenômeno em questão. É necessário compreender, contudo, que a realidade objetiva nunca será captada em sua totalidade, logo, a busca será por compreensão e profundidade, e não por validade. Como debate González Rey (2005), não podemos ignorar que cada método carrega também temas que serão estudados por meio dele, e diferentes métodos aplicados a um mesmo objeto não necessariamente levarão aos mesmos resultados.

Assim, é importante não assumir essa interação na busca por qualquer qualidade em pesquisa, pois a triangulação por si só, não serviria a esse fim específico (Flick, 2009). Já não cabe mais dizer que interações sociais podem ter maior ou menor valor se são físicas ou virtuais. Cabe agora pensar de que forma aproveitaremos esse profícuo campo de forma a mapeá-lo e, com isso, utiliza-lo nas pesquisas respeitando suas potencialidades e limites.

Há ainda a necessidade de aprofundamento teórico na análise de resultados, mas acreditamos que este trabalho cumpre seu objetivo enquanto um esforço inicial de sistematização, a partir do mapeamento realizado. Interessou-nos identificar as escolhas teórico-metodológicas realizadas e a experiência do fazer pesquisa na internet ou sobre a internet, mas consideramos que há aspectos a serem explorados em estudos futuros.

Por ser um levantamento inicial, carece de uma ampliação dos dados pesquisados, podendo ser um recurso, a busca em outras bases de dados científicos e a ampliação do número de descritores utilizados. Acreditamos ainda que o próprio conjunto dos dados possa revelar novas características que foram limitadas pela leitura restrita aos resumos, podendo a análise ser ampliada contemplando a leitura das sessões metodológicas e/ou os artigos na íntegra.

Tratando-se de um tema de estudo novo em psicologia social, a aproximação com campos como a comunicação social, ciência da informação, ciências sociais torna-se fundamental, sendo ponto de partida multidisciplinar para a ampliação das discussões sobre o tema em nossa área de conhecimento. 


\section{Referências}

Amaral, A. \& Montardo, S. (2010). Pesquisa em cibercultura e internet. Estudo exploratório comparativo da produção científica da área no Brasil e nos Estados Unidos. Revista Conexão. Comunicação e Cultura. UCS, Caxias do Sul, 9(18), 57-73. Recuperado em 09 de outubro, 2016, de http://www.ucs.br/etc/revistas/index.php/conexao/article/view/618/457

Amaral, A. \& Montardo, S. P. (2011). Pesquisa em Cibercultura: análise da produção brasileira da Intercom. LOGOS 34 O Estatuto da Cibercultura no Brasil, 1(34), 102-116. Recuperado em 19 de setembro, 2017, de http://www.logos.uerj.br/PDFS/34/08_logos34_montardo_amaral_pesquisa.pdf

Agência Minas Gerais (2016). Polícia Civil mineira é referência nacional em solução de crimes na internet. Recuperado em 19 de setembro, 2017, de http://www.agenciaminas.mg.gov.br/noticia/policia-civilmineira-e-referencia-nacional-em-solucao-de-crimes-na-internet

Araújo, R. F. (2011). Tecnologia Social da Memória (Des)Caminhos do Movimento Afro-Alagoano no Ciberespaço. Trabalho apresentado na Conference on Technology, Culture, and Memory - CTCM - Strategies for preservation and Information access. Recife: Grupo de Pesquisa Memória e Sociedade do Laboratório Liber/UFPE, Instituto Holandês do Patrimônio - Erfgoed Nederland \& Projeto Brasiliana USP. Recuperado em 28 de julho, 2014, de http://www.liber.ufpe.br/ctcm/anais/anais_ctcm/22_tecn_of_memory.pdf

Ávila, R. F. \& Monteiro, R. C. (2014). Atravessando as Ruas da Cidade: Desejo, Poder e Manifestações Sociais. Liinc em Revista, 10(1), 109-123.

Cabral Filho, A. V. \& Coutinho, G. (2009). Web 2.0: Caminhos e desafios no desenvolvimento da internet. In S. Fragoso \& A. E. Maldonado. A Internet na América Latina (pp.81-103). São Leopoldo: Ed. Unisinos; Porto Alegre: Sulina.

Castells, M. (2003). A Galáxia Internet: reflexões sobre a Internet, negócios e a sociedade. Rio de Janeiro: Zahar.

Casalegno, F. (2006). Entrevista com Serge Moscovici - Memórias, rituais e ciber-representações. In F. Casalegno. Memória cotidiana: comunidade e comunicação na era das redes (pp.70-83). Porto Alegre: Sulina.

Cerqueira, S. C. \& Rocha, C. (2013). Crimes Cibernéticos: desafios da investigação. Cadernos ASLEGIS , 49, 131161. Recuperado em 19 de setembro, 2017, de http://www.aslegis.org.br/files/cadernos/2013/caderno49/8-Crimes-ciberneticos-desafios-da-investigacao.pdf

Coimbra, C. M. B. (2001). Operação Rio: o mito das classes perigosas. Rio de Janeiro: Oficina do Autor.

De Rosa, A. S. (2005). O impacto das imagens e do compartilhamento social das emoções na construção da memória social: Uma chocante memória "flash" de massa do 11 de setembro até a guerra do Iraque. In C. P. Sá (Ed.). Memória, imaginário e representações sociais (pp. 121-164). Rio de Janeiro: Editora do Museu da República.

Flick, U. (2009). Qualidade na pesquisa qualitativa. Porto Alegre: Ed. ARTMED.

Fragoso, S. \& Maldonado, A. E. (2009). Panorama da Internet na América Latina. In S. Fragoso, A. E. Maldonado. A Internet na América Latina (pp.13-39). São Leopoldo: Ed. Unisinos; Porto Alegre: Sulina.

Fragoso, S., Recuero, R., \& Amaral, A. (2011). Métodos de pesquisa para internet. Porto Alegre: Sulina.

Gibson, W. (2003). Neuromancer. (F. Fernandes, Trad.). São Paulo: Aleph. (Original publicado em 1984).

González Rey, F. L. (2005). Pesquisa Qualitativa em Psicologia: caminhos e desafios. São Paulo: Pioneira Thomson Learning.

Henriques, R. M. N. (2014). Os rastros digitais e a memória dos jovens nas redes sociais. Tese de Doutorado, Programa de Pós-Graduação em Memória Social, Universidade Federal do Estado do Rio de Janeiro, Rio de Janeiro, RJ, Brasil.

Lemos, A. (2015). Cibercultura: tecnologia e vida social na cultura contemporânea. Porto Alegre: Sulina.

Lévy, P. (1996). O que é o virtual. (P. Neves, Trad.). São Paulo: Editora 34.

Lévy, P. (1999). Cibercultura. (C. I. Costa, Trad.). São Paulo: Editora 34. 
Lima, W. (2014). Facebook: Casos de censura no Brasil. Monografia apresentada ao Departamento de Jornalismo e Editoração da USP, São Paulo, SP, Brasil. Recuperado em 30 de março, 2014, de https://pt.scribd.com/document/355775044/Facebook-Casos-de-Censura-no-Brasil-Wilheim-RodriguesMarcelo-Lima-mestrado-pdf.

Mielniczuh, L. (2001). Considerações sobre interatividade no contexto das novas mídias. In M. Palácios, A. Lemos (Orgs.). As Janelas do Ciberespaço (pp. 172-185). Porto Alegre: Sulina.

Monteiro, S. D. (2007). O ciberespaço: o termo, a definição e o conceito. DataGramaZero-Revista de Ciência da Informação, 8(3), 1-15. Recuperado em 02 de janeiro, 2016, de http://www.datagramazero.org.br/jun07/Art_03.htm

Monteiro, S., Carelli, A., \& Pickler, M. E. (2008). A Ciência da Informação, Memória e Esquecimento. DataGramaZero-Revista de Ciência da Informação, 9(6), 1-18. Recuperado em 28 de julho, 2014, de http://www.datagramazero.org.br/dez08/Art_02.htm

NIC.br (2016). Núcleo de Informação e Coordenação do Ponto BR (ed.). Pesquisa sobre o uso das tecnologias de informação e comunicação nos domicílios brasileiros: TIC domicílios 2015. São Paulo: Comitê Gestor da Internet no Brasil.

Ribeiro, J. C. S. (2001). Um breve olhar sobre a sociabilidade no ciberespaço. In M. Palácios, A. Lemos (Orgs.). As Janelas do Ciberespaço (pp. 138-150). Porto Alegre: Sulina.

Rüdiger, F. (2013). As teorias da cibercultura: perspectivas, questões e autores. Porto Alegre: Sulina.

Sá, C. P. (2007). Sobre o campo de estudo da memória social: uma perspectiva psicossocial. Psicologia: Reflexão e Crítica, 20(2), 290-295. Recuperado em 17 de janeiro, 2016, de http://www.scielo.br/scielo.php?script=sci_arttext\&pid=S0102-79722007000200015

Santos, J. V. T. (2002). Microfísica da violência, uma questão social mundial. Ciência e Cultura, 54(1), 22-24.

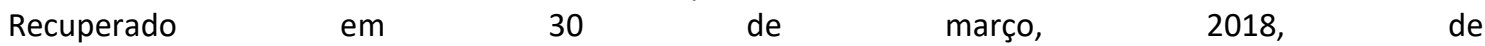
http://cienciaecultura.bvs.br/scielo.php?script=sci_arttext\&pid=S0009$67252002000100017 \&$ Ing=en\&tlng=pt.

Silva, L. O. (2001). A Internet - A Geração de um novo espaço antropológico. In M. Palácios, A. Lemos (Orgs.). As Janelas do Ciberespaço (pp. 151-171). Porto Alegre: Sulina.

Valor (2017). No Brasil, 80\% acreditam no que leem nas redes sociais. Recuperado em 20 de agosto, 2017, de http://www.valor.com.br/empresas/4870574/no-brasil-80-acreditam-no-que-leem-nas-redes-sociaisdiz-pesquisa

\title{
Notas de Fim ${ }^{\text {iii }}$
}

\begin{abstract}
' Na perspectiva de Lévy (1999), a demanda de liberação dos computadores de uso pessoal ganhou visibilidade devido ao forte movimento contracultural de jovens americanos, através de movimentos sociais como o Computers for the People, tendo efeitos no mercado ao deixar os preços acessíveis a partir da década de 1970. Já segundo Castells (2003) os jovens universitários que contribuíram para o desenvolvimento tecnológico dessa época, estariam mais interessados em seus computadores do que em questões mais amplas, ainda que a ideia de liberdade de expressão e comunicação estivesse alinhada com o espírito contracultural de seu tempo, estes não podem ser tidos como representantes desse movimento.
\end{abstract}

ii Levantamento feito pela rede $B B C$ de Londres. Matéria disponível em: http://www.bbc.co.uk/portuguese/noticias/2011/07/110718_magnatas_bg_cc.shtml 